\title{
ESTATUTO ORGÁNICO DE LA UNIVERSIDAD DE CHILE (1971) ${ }^{1}$
}

\section{Ministerio de Educación Pública}

El estatuto orgánico de la Universidad de Chile es un texto legal fundamental. Haciendo una analogía, es para nuestra institución lo que es la Constitución para el país. En este se establece la misión y principios de nuestra Universidad, así como también sus organismos y atribuciones, la estructura institucional, la composición de la comunidad universitaria y la organización de los estudios universitarios, entre otras materias. Se trata de una ley que debe aprobar el Congreso y dictar la Presidencia de la República. Este reglamente fue aprobado por el Decreto con Fuerza de Ley No1 del 4 de junio de 1971 y es el resultado de la Reforma Universitaria, es decir, del proceso de transformación política, administrativa, social y cultural que comenzó en 1967. Una vez sintetizadas sus conclusiones, en 1970 el Consejo Universitario lo aprobó en conformidad con el principio de "autonomía universitaria" que estaba garantizado por la Constitución Política de 1925. En él se define a la institución de esta manera: "La Universidad de Chile es una comunidad democrática, fundamentalmente creadora y crítica que, a través del desenvolvimiento y estímulo de todas las formas superiores de actividad intelectual, y del ejercicio de sus funciones esenciales -investigación, creación artística, docencia y extensión - asegura la continuidad y recreación de la cultura. En el cumplimiento de sus objetivos, la Universidad asume su responsabilidad específica en la formación de una conciencia objetiva y crítica de la sociedad chilena, y, a través de su aporte humanístico, contribuye a conformar la voluntad de cambios necesaria para conquistar un orden de convivencia que garantice la participación de todos los miembros de la comunidad nacional. La realización de estas tareas hace necesaria una estructura democrática de la Universidad y la integración y correlación adecuadas de los diferentes estamentos que la constituyen".

Alguno de sus principios centrales eran: el cogobierno, concepto inherente a la noción de autonomía universitaria expresado en la participación democrática de los

1. Ministerio de Educación del Gobierno de Chile (1982 [1971]). DFL 1 Aprueba Estatuto Orgánico de la Universidad de Chile. Promulgación: 4 de junio 1971. Publicación: 8 de junio de 1971. Última Versión: 19 de enero de 1982. Biblioteca del Congreso Nacional, pp. 1-4. Disponible en: https://www.bcn.cl/leychile/navegar?i=3380\&f=1982-01-19\&p= 
diversos estamentos que componen la comunidad; la comprensión de la universidad como un sistema estatal unitario, descentralizado y presente en todo el país a través de sus sedes regionales (Arica, Iquique, Antofagasta, La Serena, Valparaíso, Talca, Nuble, Temuco, Osorno y Santiago); el pluralismo que garantiza la libre expresión y coexistencia pacífica de las distintas ideologías presentes sin otra limitación que el respeto mutuo. Para estos efectos se estableció la inviolabilidad de los recintos universitarios de manera que ninguna autoridad ajena a ella podría ejercer sus atribuciones sin la anuencia de las autoridades universitarias correspondientes. También se establecía que las funciones de la casa de estudios eran la investigación, la creación artística, la docencia y la extensión, ejercidas de forma integrada, armónica e interdependiente, superando la desvinculación estructural que caracterizaba a la antigua universidad oligarca decimonónica.

Este estatuto fue suspendido por la dictadura militar en 1973 para luego ser derogado en 1982. La Constitución de 1980 abolió el principio de "autonomía universitaria" que garantiza la libertad subyacente en dicho espacio académico sin intervenciones de los gobiernos de turno. Años más tarde y, tras las movilizaciones estudiantiles de 1997, se inició otro referéndum del cual derivó el estatuto vigente desde el año 2005. En las discusiones del año 1997 el antiguo estatuto estuvo muy presente. Existen ejemplares físicos en las facultades de Arquitectura y Urbanismo, de Ciencias Veterinarias y Pecuarias y en la Facultad de Derecho, según señala la descripción catalográfica en una separata de la serie Informaciones y Documentos Universitarios que contiene los discursos pronunciados por el presidente de la República, el ministro de Educación y el rector subrogante de la Universidad de Chile. 


\section{Biblioteca del Congreso
Nacional de Chile/BCN Ley Chile}

\section{Decreto con Fuerza de Ley 1} APRUEBA ESTATUTO ORGANICO DE LA UNIVERSIDAD DE CHILE MINISTERIO DE EDUCACIÓN PÚBLICA

Fecha Publicación: 08-JUN-1971 | Fecha Promulgación: 04-JUN-1971 Tipo Versión: Última Versión De : 19-ENE-1982

Texto derogado: 19-ENE-1982

Url Corta: $h$ ttp://bcn.cl/2i57m

APRUEBA ESTATUTO ORGANICO DE LA UNIVERSIDAD DE CHILE

NOTA Núm. 1.- Santiago, 4 de Junio de 1971.

Vistos: las facultades que me confiere la ley $\mathrm{N}^{\circ}$

17.434, publicada en el Diario Oficial de fecha 21 de

Mayo de 1971; el proyecto de Estatuto orgánico de la

Universidad de Chile aprobado por el Congreso

Universitario transitorio y las modificaciones

introducidas por el Parlamento Nacional conforme se

establece en la ley citada, dicto el siguiente

Decreto con fuerza de ley:

ESTATUTO ORGANICO DE LA UNIVERSIDAD DE CHILE

NOTA :

El DFL 153, Hacienda, publicado el 19.01.1982

derogó el presente decreto.

TITULO I \{ARTS. 1-8

DISPOSICIONES FUNDAMENTALES

Articulo $1^{\circ}$ La Universidad de Chile es una comunidad democrática, fundamentalmente creadora y crítica que, a través del desenvolvimiento y estímulo de todas las formas superiores de actividad intelectual, y del ejercicio de sus funciones esenciales -investigación, creación artistica, docencia y extensión- asegura la continuidad y recreación de la cultura.

En el cumplimiento de sus objetivos, la Universidad asume su responsabilidad específica en la formación de una conciencia objetiva y critica de la sociedad chilena, y, a través de su aporte humanístico, contribuye a conformar la voluntad de cambios necesaria para conquistar un orden de convivencia que garantice la participación de todos los miembros de la comunidad nacional.

La realización de estas tareas hace necesaria una estructura democrática de la Universidad y la integración y correlación adecuadas de los diferentes estamentos que la constituyen.

Articulo $2^{\circ}$ La Universidad de Chile es una Universidad nacional. Como tal, orienta preferentemente su acción a los problemas del país y extiende sus actividades a todo el territorio de la República. Sus diversos órganos

constituyen un sistema estatal unitario, de funcionamiento 
Biblioteca del Congreso

Nacional de Chile / BCN Ley Chile

descentralizado, coordinados por un gobierno central.

Ninguno de ellos podrá segregarse sino por voluntad de toda la comunidad universitaria y en virtud de una ley.

Artículo $3^{\circ}$ La Universidad de Chile es democrática.

Participan en su gobierno todos los miembros de la comunidad universitaria tal como se establece en el presente Estatuto.

El acceso, la permanencia, transferencia y promoción de sus miembros tienen lugar sólo en virtud de sus méritos, sin discriminación de ninguna especie.

Artículo $4^{\circ}$ La Universidad de Chile garantiza a todos sus miembros dentro de cada una de sus estructuras y organismos, y a cualquiera dentro de su ámbito, la libre expresión y coexistencia de las diversas ideologías y corrientes de pensamiento, sin otra limitación que su ejercicio se sujete a normas de respeto mutuo.

Para este efecto los recintos universitarios son inviolables y ninguna autoridad ajena a la Corporación o sus representantes podrá ejercer sus atribuciones en ellos sin anuencia de la autoridad universitaria que corresponda.

Artículo $5^{\circ}$ La Universidad de Chile es un establecimiento público, autónomo, independiente de la administración central del Estado. Es una persona jurídica de derecho público, con patrimonio propio y con domicilio en la ciudad de Santiago. Su representante legal es el Rector.

La Universidad de Chile tiene derecho a establecer y mantener relaciones con todas las entidades nacionales internacionales o extranjeras, y a acreditar representantes ante ellas para los fines que estime convenientes.

Articulo $6^{\circ}$ Corresponde privativamente a la Universidad de Chile, en virtud de su autonomía, la potestad de regirse, gobernarse, organizarse y determinar el sentido, la forma y condiciones de su actividad, según mejor convenga a sus propios fines y conforme a su sola voluntad, expresada del modo previsto en esta ley y en los reglamentos que la autoridad universitaria dicte.

De la misma manera, le corresponde privativamente determinar sus funciones y actividades académicas, la forma de administrarse, la planificación de su acción y desarrollo, la distribución de su presupuesto y, general, la realización de todos aquellos actos y modos que requieran las funciones que le son propias.

Artículo $7^{\circ}$ la facultad de decidir sobre la marcha académica de la Universidad de Chile, sobre el modo de gobernarla y administrarla y sobre la manera de realizar las funciones respectivas, reside esencialmente en los miembros de la comunidad universitaria, dentro de los límites y en la proporción y forma determinados en este Estatuto.

La presente ley señala los casos en que corresponde a 


\section{\begin{tabular}{c|c} 
Biblioteca del Congreso \\
Nacional de Chile/BCN
\end{tabular}}

DFL 1, EDUCACIÓN (1971)

la propia comunidad universitaria ejercer directamente esta facultad, y aquellos en que la delega en autoridades mandatarias que la representan. Estas serán colegiadas o unipersonales, con funciones y atribuciones regladas, elegidas por un tiempo determinado $\mathrm{y}$, en todo caso, responsables de su gestión ante la misma comunidad.

Articulo $8^{\circ}$ Las disposiciones del presente estatuto y de los reglamentos universitarios se considerarán de carácter especial frente a toda ley que en cualquier forma o sentido sean con ellos incompatible. Por tanto, ninguna ley prevalecerá sobre lo que en ellos se establezca, ni se entenderá que deroga sus disposiciones, salvo que de manera expresa así lo prescriba.

Siempre que las leyes se refieran a normas

reglamentarias, tal referencia deberá entenderse hecha, respecto de la Universidad de Chile, a los reglamentos que dicte el Consejo Superior.

TITULO II \{ARTS. 9-52\}

ESTRUCTURA Y GOBIERNO

Párrafo $1^{\circ}$ \{ARTS. 9-12

Estructura

Artículo $9^{\circ}$ Los Departamentos son las unidades académicas básicas de la estructura universitaria encargadas de proyectar, orientar, organizar, realizar y evaluar integradamente la investigación científica y tecnológica, la expresión o creación artística, la docencia y la extensión universitaria en el campo de la cultura que el Consejo Normativo Superior haya situado en el ámbito de su responsabilidad. Tendrán, además, las otras funciones que los reglamentos les señalen.

Los Departamentos son indivisibles en cuanto a su gobierno y administración; poseen rango universitario equivalente, y estarán o no asociados en Facultades en la forma y condiciones que determine el Consejo superior de la Universidad.

Artículo $10^{\circ}$ Las Facultades son organismos de gobierno encargadas de desarrollar una tarea permanente en un campo cultural mayor que el propio de los Departamentos. Están constituidas por Departamentos cuya actividad está orientada a objetivos comunes, análogos o complementarios y que, por decisión del Consejo Superior, se agrupan para coordinar sus actividades académicas y administrativas.

Artículo $11^{\circ}$ Las Sedes son las unidades mayores de la Universidad. Están compuestas por Departamentos asociados no en Facultades $y$ se vinculan directamente con el Gobierno Central de la Universidad.

Cada sede tendrá unidad territorial, un tamaño crítico funcional y un importante grado de autonomía administrativa, financiera y de gobierno; procurará cultivar con su acción académica los diversos campos generales de la cultura al más alto nivel posible, no obstante lo cual, podrá poner especial énfasis en el 


\section{\begin{tabular}{l|l} 
Biblioteca del Congreso & Ley Chile \\
Nacional de Chile/BCN & Ley Con
\end{tabular}}

desarrollo de algunas áreas del conocimiento.

Las Sedes propenderán con su actividad al

desenvolvimiento de la región en que estén situadas.

Artículo $12^{\circ}$ La labor academica de la Universidad de Chile será complementada por organismos técnicos. administrativos y de servicios, los que podrán depender del gobierno central de la Universidad, de las Sedes, de las Facultades o de los Departamentos.

La creación, organización, modalidad de operación, supresión, descentralización y definición de objetivos será determinada por el Consejo Superior de la Universidad, quien, en el caso de descentralizar un organismo, señalará su adscripción a un determinado nivel de la estructura acadèmica.

En esta categoría podrán crearse organismos con el propósito de realizar una función académica específica, la que por su campo restringido o su desarrollo incompleto, no cumple con los requisitos establecidos para la constitución de estructuras académicas.

Será tarea de estos organismos la administración

interna universitaria, el apoyo y colaboración técnica a los programas académicos, la vinculación con la comunidad nacional y el extranjero y todas aquellas que les asignen los reglamentos, de acuerdo a las necesidades de la entidad académica a que están adscritas.

\section{Párrafo $2^{\circ}$ \{ARTS. 13-41\}}

Gobierno

NORMAS COMUNES \{ARTS. 13-25\}

Articulo $13^{\circ}$ Las autoridades de la Universidad de Chile son colegiadas y unipersonales.

Son autoridades colegiadas los Claustros, los Consejeros Normativos y los Comités Directivos.

Las autoridades unipersonales son el Rector y el Secretario General, los Vicerrectores y secretarios de Sedes, los Decanos y Secretarios de Facultades, los Directores y Secretarios de Departamentos.

Artículo $14^{\circ}$

La comunidad universitaria está integrada por sus funcionarios y estudiantes, quienes participan en el gobierno de la Universidad con la ponderación de:

Funcionarios académicos

Funcionarios profesionales, técnicos,

administrativos y de servicio Estudiantes

Artículo $15^{\circ}$ Los Claustros estarán constituidos por los miembros de la respectiva comunidad definidos en el presente Estatuto. En ellos reside la facultad de gobernar la Universidad de Chile y su voluntad se expresa a través de elecciones y de consultas plebiscitarias.

Habrá un Claustro en cada Departamento, en cada Facultad y en cada sede. Habrá, además, un Claustro Pleno.

Los Claustros serán convocados ordinariamente por la 